\title{
Measurement matters: Higher waist-to-hip ratio but not body mass index is associated with deficits in executive functions and episodic memory
}

\author{
Andree Hartanto ${ }^{\text {Corresp.., }}{ }^{1}$, Jose C. Yong ${ }^{1,2}$ \\ ${ }^{1}$ School of Social Sciences, Singapore Management University, Singapore, Singapore \\ 2 National University of Singapore, Singapore, Singapore \\ Corresponding Author: Andree Hartanto \\ Email address: andreeh.2014@phdps.smu.edu.sg
}

Background. The current study aimed to reconcile the inconsistent findings between obesity, executive functions, and episodic memory by addressing major limitations of previous studies, including overreliance on body mass index (BMI), small sample sizes, and failure to control for confounds.

Methods. Participants consisted of 3,712 midlife adults from the Cognitive Project of the National Survey of Midlife Development. Executive functions and episodic memory were measured by a battery of cognitive function tests

Results. We found that higher waist-to-hip ratio was associated with deficits in both executive functions and episodic memory, above and beyond the influence of demographics, comorbid health issues, health behaviours, personality traits, and self-perceived obesity. However, higher BMI was not associated with deficits in executive functions and episodic memory. More importantly, these differential associations were robust and stable across adulthood.

Discussion. Our findings confirm the association between obesity and episodic memory while highlighting the need for better measures of obesity when examining its associations with individual differences in cognitive functions. 
1 Running Head: Obesity, Executive Functions, and Episodic Memory

2

3

4

5

6

7

8 Measurement Matters: Higher Waist-to-hip Ratio but not Body Mass Index is Associated

18 Andree Hartanto, $\mathrm{PhD}$

19 Singapore Management University

20 School of Social Sciences

2190 Stamford Road, Level 4

22 Singapore 178903

23

24 Email: andreeh@smu.edu.sg

25 Phone: (65) 68281901
Andree Hartanto ${ }^{1}$ and Jose C. Yong ${ }^{12}$

${ }^{1}$ Singapore Management University

${ }^{2}$ National University of Singapore 
Abstract

27 Background. The current study aimed to reconcile the inconsistent findings between obesity,

28 executive functions, and episodic memory by addressing major limitations of previous

29 studies, including overreliance on body mass index (BMI), small sample sizes, and failure to

30 control for confounds.

31 Methods. Participants consisted of 3,712 midlife adults from the Cognitive Project of the

32 National Survey of Midlife Development. Executive functions and episodic memory were

33 measured by a battery of cognitive function tests

34 Results. We found that higher waist-to-hip ratio was associated with deficits in both

35 executive functions and episodic memory, above and beyond the influence of demographics,

36 comorbid health issues, health behaviours, personality traits, and self-perceived obesity.

37 However, higher BMI was not associated with deficits in executive functions and episodic memory. More importantly, these differential associations were robust and stable across adulthood.

40 Discussion. Our findings confirm the association between obesity and episodic memory while highlighting the need for better measures of obesity when examining its associations with individual differences in cognitive functions. 
51 Measurement Matters: Higher Waist-to-hip Ratio but not Body Mass Index is Associated

High levels of adiposity, manifested as being overweight to obese, is a significant and

growing challenge to public health (Clark et al., 2016). As a recognized risk factor for a wide

range of chronic diseases such as metabolic syndrome, diabetes, hypertension, cardiovascular

disease, stroke, and certain types of cancer (Kopelman, 2000), obesity carries a heavy

economic burden for governments and healthcare providers across the world (Avenell et al.,

2004). Concerns over the dangers of obesity are further heightened by its increasing

prevalence in both developed and developing countries, with approximately $30 \%$ of the

world's population being either obese or overweight ( $\mathrm{Ng}$ et al., 2014)

While obesity undoubtedly correlates with various undesirable physical health

outcomes, there is growing evidence that obesity is also associated with deficits in cognitive

functions independent of health conditions that comorbid with obesity (Whitmer et al., 2008;

Anstey, Cherbuin, Budge, \& Young, 2011; Beydoun, Beydoun, \& Wang, 2008). Two main

cognitive aspects tend to be emphasized. First, obesity is associated significantly with impairment of executive functions (Sellaro \& Colzato, 2017; Smith, Hay, Campbell, \& Trollor, 2011), which are high-level cognitive processes that enable the regulation of thoughts and behaviour to achieve goals (Friedman \& Miyake, 2017). A number of studies have observed that body mass index (BMI) correlates with poorer performance in core components of executive functions, such as inhibitory control, cognitive flexibility, and working memory across different age groups (Cserjési, Luminet, Poncelet, \& Lénárd, 2009; Goldschmidt et al., 2017; Kesse-Guyot et al., 2015; Reinert, Po'e, \& Barkin, 2013; Sellaro \& Colzato, 2017; Smith et al., 2011). Importantly, the mechanism underlying these relationships is argued to be bidirectional (Kanoski \& Davidson, 2011; Sellbom \& Gunstad, 2012). On the one hand, 
76 obesity may arise from poor impulse control such that the inability to resist the urge to eat

77 causes overconsumption (Dohle, Diel, \& Hofmann, 2017; Wu et al., 2016). On the other

78 hand, emerging animal and human research also indicates that excessive body fat percentages

79 cause neurological changes such as reduced cerebral metabolism, elevated leptin,

80 hippocampal volume reduction, and neuronal degradation (Erion et al., 2014; Harvey, 2007;

81 Raji et al., 2010; Smith et al., 2011; Volkow et al., 2009) which can lead to declines in

motivation, self-control, and cognition (Figley, Asem, Levenbaum, \& Courtney, 2016).

A second account links obesity with impairment of episodic memory, which is the

ability to store mental representations of events that one has experienced or observed

(Tulving, 2002). Episodic memory has been shown to play a significant role in the regulation of consumption (Brunstrom et al., 2012; Higgs \& Donohoe, 2011; Martin, Davidson, \&

McCrory, 2017). For example, amnesic patients who cannot remember prior episodes of food or uncomfortable (Hebben, Corkin, Eichenbaum, \& Shedlack, 1985; Higgs, Williamson,

Rotshtein, \& Humphreys, 2008). Studies on rodents have found robust evidence for memory deficits which arise from hippocampal abnormalities caused by obesity (Jurdak, Lichtenstein, \& Kanarek, 2008; Valladolid-Acebes et al., 2011), thus suggesting that obesity can undermine episodic memory through neurological structural changes the same way that obesity affects brain structure and executive function. However, evidence from studies on humans for any adverse impacts of obesity on episodic memory is far less robust. Although some studies have observed a significant association between higher BMI and poorer episodic memory in young and old adults (e.g., Gunstad et al., 2008; Gunstad, Paul, Cohen, Tate, \& Gordon, 2006), a number of other studies failed to find any such associations (e.g., 
100 Sullivan, Wolf, \& D’Agostino, 2005; Nilsson \& Nilsson, 2009; Knopman et al., 2001; Sabia,

101 Kivimaki, Shipley, Marmot, \& Singh-Manoux, 2009; Singh-Manoux \& Marmot, 2005).

difficult to observe, Cheke, Simons, and Clayton (2016) recently claimed to have found empirical evidence for a direct relationship between higher BMI and poorer episodic memory which was assessed using a Treasure Hunt Task requiring subjects to recall the what, where, and when (WWW) elements of an episode, thus providing new supporting evidence for the negative relationship between obesity and episodic memory. Although the study is contextually rich multidimensional episodic recollection, the study has been criticized most notably by Cole and Pauly-Takacs (2016) for a number of limitations, including its relatively small sample size $(n=60)$, failure to control for health conditions that comorbid with obesity (e.g., hypertension, diabetes), and the diminished association between BMI and episodic memory when demographic factors such as age, sex, and education were included in the model. These limitations prompted Cole and Pauly-Takacs to warn that the conclusions are potentially misleading and that the findings should be interpreted with greater caution.

Despite the inconclusive link between obesity and episodic memory, we argue that the inconsistent findings thus far could be due to an overreliance on BMI to operationalize obesity in most studies. Although BMI is currently the most popular index of adiposity, it has received its fair share of criticism (Gallagher et al., 1996; Rothman, 2008). BMI is calculated as an individual's weight divided by their height squared, but the measurement of weight neither discriminates between muscle and adipose tissue nor does it directly assess regional adiposity (Stevens, McClain, \& Truesdale, 2008), and the measurement of height does not account for the possibility of shrinkage and vertebral collapse (Price, Uauy, Breeze, Bulpitt, \& Fletcher, 2006). Rothman (2008) also argued that the use of BMI as a measure of obesity 
125 produces a bias toward or away from the null in estimating effects related to obesity. As an

126 alternative, some researchers have found waist-to-hip ratio (WHR) to be superior to BMI,

127 demonstrating in some studies that WHR correlates more highly with health risk factors such

128 as cardiovascular disease, diabetes, and even mortality than BMI does (Janssen, Katzmaryzk,

$129 \&$ Ross, 2004; Price et al. 2006; Zhu et al., 2005). Thus, re-examinations of obesity and

130 various markers of cognition using alternative indices of adiposity while accounting for the

131 shortcomings of prior research will contribute significantly to the unresolved debate on

132 whether high levels of adiposity are indeed associated with episodic memory deficits in

133 humans.

\section{The Current Study}

With these issues in mind, the current study sought to re-examine the relationship

between obesity and episodic memory while (1) taking into account WHR as a potentially

better indicator of obesity and (2) addressing the methodological limitations of previous

studies related to sample size, comorbidity, and other possible confounding variables such as demographics and personality. Here, we analysed a large-scale dataset from the Cognitive

Project of the National Survey of Midlife Development, Second Wave, in the United States

(MIDUS II: Cognitive Project), which offers an opportunity to examine the relationship

between obesity and episodic memory with a large sample and WHR as a measure of obesity. Importantly, each participant in the MIDUS II was provided with a tape measure to ensure the accuracy of reported body measurements. Moreover, the study collected detailed information regarding participants' demographics, comorbid health conditions, health behaviours, personality, and even self-perceived obesity, which allowed us to determine whether any associations found between obesity and episodic memory exist above and beyond the influence of these potential confounding variables (Bendayan, Piccinin, Hofer, \& Muniz, 2016; Cole and Pauly-Takacs, 2016; Crowe et al., 2010; Dunai, Labuschagne, Castle, 
150 Kyrios, \& Rossell, 2010; Hartanto, Toh, \& Yang, 2016; Hartanto \& Yang, 2018; Ihle et al.,

151 2017; Williams, Suchy, \& Kraybill, 2010). Lastly, participants were administered a

152 comprehensive battery of executive function tasks, which allows us to simultaneously

153 examine the two cognitive functions regarded as most essential to regulating consumption

154 behaviours - executive functions and episodic memory (Higgs et al., 2008).

In summary, using a large sample provided by the MIDUS II, we examined the

predictability of BMI and WHR on executive functions and episodic memory after

controlling for confounding variables. Specifically, we hypothesized that WHR would be a

significant predictor of executive functions and episodic memory, even after controlling for

participants' demographics, comorbid health conditions, health behaviours, personality, and even self-perceived obesity. In contrast, based on the shortcomings of BMI as a measure of obesity, we hypothesized that BMI would not be a significant predictor of executive functions and episodic memory especially when confounding factors are taken into account.

\section{Method}

\section{Participants}

The sample consisted of 4,206 participants from the Cognitive Project of the National Survey of Midlife Development, Second Wave, in the United States (MIDUS II: Cognitive Project; Ryff \& Lachman, 2010). MIDUS II was conducted in 2004-2006 on a nationally representative random-digit-dial sample of non-institutionalized, English-speaking adults (see Ryff et al., 2007 for more details). As the self-administered questionnaire contained the key predictors (BMI and WHR) and most of the covariates (e.g., health status, personality traits, etc) of interest to the current study, we excluded participants who did not complete the selfadministered questionnaire $(n=494)$. After exclusions, the final sample size was 3,712 .

Table 1 summarized the demographic, health-related, and personality characteristics of the 
175 sample. The data collection for the MIDUS project was approved by the Education and

176 Social/Behavioral Sciences and the Health Sciences Institutional Review Board at the

177 University of Wisconsin-Madison (H-2008-0060). All participants have provided informed

178 consent. Data and materials from the MIDUS II: Cognitive Project are freely available from

179 the Inter-University Consortium for Political and Social Research

180 (http://www.icpsr.umich.edu).

[Table 1 near here]

\section{Measures}

Cognitive ability. Episodic memory and executive functions were assessed with the

Brief Test of Adult Cognition by Telephone (BTACT; Lachman \& Tun, 2008; Tun \& Lachman, 2006). The BTACT is a battery of cognitive function tests which comprise the Immediate Word List Recall Task, Backward Digits Span, Categorical Fluency, Stop and Go confirmatory factor analyses of the seven cognitive tests show that the data fits a two-factor model of episodic memory and executive functions (Lachman \& Tun, 2008). Episodic memory is best represented by performance on the immediate word list recall and delayed word list recall while executive function is best represented by performance on the backward digit span, categorical fluency, number series, backward counting, and SGST. Following the recommendations of Lachman and Tun, we computed composite scores for episodic memory and executive functions from standardized scores of the respective subtests, with a mean of zero and a standard deviation of one (see Lachman \& Tun, 2008 for more details). 
Obesity. Obesity was indexed by BMI and WHR. BMI was calculated by

participants' self-reported weight and height based on the formula where BMI equals to around the navel to their hips at the widest point. During the data collection, participants were provided with a tape measure to ensure the accuracy of the reported body measurements.

Participants were instructed to stand upright and keep the tape measure taut to the body when making the measurements (e.g., avoid draping the tape measure loosely over their clothing).

Participants were also specifically instructed to measure at the level of their navel for the waist measurement and at the widest point between their waist and thighs for the hip measurement. Following Preston, Fishman, and Stokes' (2015) recommendations, we operationalized BMI and WHR as a continuous variable to minimize bias associated with treating obesity as a categorical variable while keeping the operationalization of both BMI and WHR consistent.

\section{Data analysis}

We examined the influence of BMI and WHR on episodic memory and executive functions. For each criterion, we performed ordinary least squares regression models with BMI and WHR as separate predictors to minimize multicollinearity. Each predictor-criterion pair consisted of four models, with each model consisting of an additional set of covariates that have been linked to episodic memory and executive functions to ensure the robustness of the hypothesized associations. Our analyses were performed using IBM SPSS Statistics Version 25.

In the first model, we included participants' demographics such as age, sex, education attainment, household income, and subjective social status as measured by the MacArthur 
222 attainment was rated on a scale of 1 (No school) to 12 (Ph.D, ED. D, MD, LLB, LLD, JD, or

223 other professional degree). Socioeconomic status indices, such as education attainment,

224 household income, and subjective social status, have been shown to be significant and thus

225 important predictors of interindividual variability in cognitive functions (Gianaros et al., 226 2007; Hackman, Farah, \& Meaney, 2010; Zhang, Fung, \& Kwok, 2017). In the second

227 model, we included comorbidities of obesity that have been found to be associated with cognitive decline, such as hypertension, diabetes, and stroke (e.g., Crowe et al., 2010; Ihle et al., 2017). We also controlled for self-reported physical health and the total number of chronic diseases experienced in the past 12 months as general indicators of health status (Bendayan et al., 2016). In addition, we included health-impacting behaviours such as smoking, alcohol consumption, and physical activity. Following Lee (2015), physical activity was based on the average of four self-reported items that assessed the frequency of vigorous and moderate physical activity in both summer and winter seasons (e.g., "How often do you engage in vigorous physical activity that causes your heart to beat so rapidly that you can feel it in your chest and you perform the activity long enough to work up a good sweat and are breathing heavily? (Examples: competitive sports like running, vigorous swimming, or high intensity aerobics; digging in the garden, or lifting heavy objects.)." In the third model, we included the Big Five personality traits as covariates (extraversion, conscientiousness, agreeableness, neuroticism, and openness to experience; Rossi, 2001) to ensure that individual personality characteristics are not a confounding factor (Williams et al., 2010). In the last model, we included self-perceived obesity as a covariate to rule out the possibility that the hypothesized associations might be due to psychological issues associated with how obese participants believed themselves to be (e.g., body dysmorphic disorder, low selfconfidence) rather than actual physical obesity (Dunai et al., 2010). We further conducted 
246 slope differentiation tests to examine the predictability differences between BMI and WHR

247 on episodic memory and executive functions.

In addition, we conducted moderation analyses separately to examine whether age moderates the predictability of BMI and WHR. Age was explored as a moderator due to the possibility that the lack of a relationship between BMI and cognitive functions is limited only to older adults, as BMI may not be sensitive to shrinkage and vertebral collapse as a function of age (Price et al., 2006). Here, we reconducted our analyses by including the interaction terms between BMI and age or WHR and age in each model. Furthermore, given that males and females differ in adipose tissue distribution and expansion (Zore, Palafox, Reue, 2018), we also conducted separate analyses to examine whether the predictability of BMI and WHR would be moderated by sex. At the end of our analyses, we also conducted polynomial regressions for each model to examine the quadratic influence of BMI and WHR on episodic memory and executive functions due to the possible cognitive consequences of extremely low weight individuals.

In each model, BMI, WHR, and number of chronic conditions were winsorized to minimize the influence of outliers. Age, education, household income, subjective social status, number of chronic diseases, the Big Five personality traits, and self-perceived obesity were mean-centred to improve the interpretation of intercept terms. In our moderation analyses, BMI and WHR were mean-centred. For missing data in our datasets, we performed multiple imputations (Rubin, 1987) using a Markov chain Monte Carlo algorithm with a fully conditional specification procedure to create five imputed datasets. As recommended by Von Hippel (2007), we employed the multiple-imputation-then-deletion procedure in which missing criterion variables were excluded from the analysis subsequent to the imputation. 
270 covariates of our regression models had tolerance values lower than .10 or variance inflation

271 factor values larger than 10 (O’Brien, 2007; York, 2012).

\section{Results}

BMI

Our models for the effect of BMI on episodic memory and executive functions are summarized in Table 3. After controlling for demographic variables in the first model, we observed that BMI was negatively associated with episodic memory $(B=-.007, S E=.003,95 \%$ $\mathrm{CI}=[-.012,-.002], p=.009)$. However, this significant association diminished when we included health status and health behaviours as covariates in the second model $(B=-.001$, $S E=.003,95 \% \mathrm{CI}=[-.007, .004], p=.640)$, personality variables in the third model $(B=-.002$, $S E=.003,95 \% \mathrm{CI}=[-.007, .004], p=.567)$, and self-perceived obesity in the fourth model $(B=-$ $.002, S E=.004,95 \% \mathrm{CI}=[-.010, .006], p=.617)$. negatively associated with executive functions after controlling for demographic variables in the first model $(B=-.007, S E=.002,95 \% \mathrm{CI}=[-.011,-.002], p=.007)$, but the significant association diminished when we included health status and health behaviours as covariates in the second model $(B=.002, S E=.003,95 \% \mathrm{CI}=[-.003, .007], p=.422)$, personality variables in the third model $(B=.002, S E=.003,95 \% \mathrm{CI}=[-.003, .007], p=.545)$, and self-perceived obesity in the fourth model $(B=-.004, S E=.004,95 \% \mathrm{CI}=[-.011, .002], p=.204)$. These results suggest that the significant prediction of BMI on episodic memory and executive functions in the first model could be driven by health issues comorbid with obesity that have been associated with cognitive decline. 
294 Waist-to-hip ratio

295

296

297

298

299

300

301

302

303

304

305

306

307

308

309

310

311

312

313
Our models for the effect of WHR on episodic memory and executive functions are summarized in Table 4. Similar with BMI, we observed that WHR was negatively associated with episodic memory after controlling for demographic variables in the first model $(B=-$ $.657, S E=.179,95 \% \mathrm{CI}=[-1.009,-.305], p<.001)$. However, in contrast to BMI, WHR remained a significant predictor of episodic memory after we included health status and health behaviours as covariates in the second model $(B=-.469, S E=.179,95 \% \mathrm{CI}=[-.821$, $.117], p=.009)$, personality variables in the third model $(B=-.447, S E=.180,95 \% \mathrm{CI}=[-.800$, .095], $p=.013)$, and self-perceived obesity in the fourth model $(B=-.454, S E=.183,95 \% \mathrm{CI}=[-$ $.814,-.095], p=.013)$. When similar analyses were performed for executive functions, we also found that WHR was a significant predictor of executive functions after we controlled for demographic variables in the first model $(B=-.856, S E=.161,95 \% \mathrm{CI}=[-1.172,-.540]$, $p<.001)$, health status and health behaviours in the second model $(B=-.659, S E=.160,95 \%$ $\mathrm{CI}=[-.869,-.241], p=.001)$, personality variables in the third model $(B=-.565, S E=.160,95 \%$ $\mathrm{CI}=[-.880,-.250], p<.001)$, and self-perceived obesity in the fourth model $(B=-.659, S E=.163$, $95 \% \mathrm{CI}=[-.980,-.339], p<.001)$.

We further conducted slope differentiation tests between BMI and WHR. Crucially, in all models we examined, we consistently found significantly lower coefficient estimates for BMI than WHR ( $p$ s $<.05)$, suggesting that WHR is related more strongly to episodic memory and executive functions than BMI. Taken together, our results demonstrate that higher WHR is associated with poorer episodic memory and executive functions, and that this effect persists beyond the influence of demographics, comorbid health issues, health status, health behaviours, personality traits, and self-perceived obesity.

[Table 4 near here] 
In our additional moderation analyses for BMI, we did not observe any significant

interactions between BMI and age in predicting episodic memory in all of our models; Model

$1(95 \% \mathrm{CI}=[-.001, .000] ;$ Beta $=-.009, p=.553)$, Model $2(95 \% \mathrm{CI}=[-.001, .000]$, Beta $=-.009$,

$p=.437)$, Model $3(95 \% \mathrm{CI}=[-.001, .000]$, Beta=-.012, $p=.422)$, Model 4 (95\% CI=[-.001,

$.000]$, Beta $=-.012, p=.415)$. There was also no significant interaction between BMI and age in

predicting executive functions in Model $1(95 \% \mathrm{CI}=[.000, .001]$; Beta $=.018, p=.208)$, Model

$2(95 \% \mathrm{CI}=[.000, .001]$, Beta $=.015, p=.274)$, Model $3(95 \% \mathrm{CI}=[.000, .001]$, Beta $=.015$,

$p=.265)$, and Model $4(95 \% \mathrm{CI}=[.000, .001], \operatorname{Beta}=.012, p=.375)$.

Similarly, in our additional moderation analyses for WHR, the interaction term

between WHR and age did not significantly predict episodic memory in any of the four models; Model $1(95 \%$ CI=[-.044, .002]; Beta=-.027, $p=.071)$, Model $2(95 \% \mathrm{CI}=[-.045$, $.000]$, Beta $=-.029, p=.051)$, Model 3 (95\% CI=[-.044, .001], Beta=-.028, $p=.065)$, Model 4 $(95 \% \mathrm{CI}=[-.044, .001]$, Beta $=-.028, p=.065)$. Similarly, the interaction term between WHR and age did not significantly predict executive functions in any of the models; Model 1 (95\% $\mathrm{CI}=[-.032, .010] ;$ Beta $=-.014, p=.307)$, Model $2(95 \% \mathrm{CI}=[-.033, .008]$, Beta $=-.016, p=.242)$,

Model $3(95 \%$ CI $=[-.032, .008]$, Beta $=-.016, p=.251)$, Model $4(95 \%$ CI $=[-.032, .008]$, Beta $=-$ episodic memory and executive functions is consistent and robust across adulthood.

\section{Sex as moderator}

340 predicting episodic memory across our four models; Model $1(95 \% \mathrm{CI}=[-.010, .012]$;

341 Beta $=.005, p=.797)$, Model $2(95 \% \mathrm{CI}=[-.009, .013]$, Beta $=.006, p=.749)$, Model $3(95 \%$ 
$342 \mathrm{CI}=[-.010, .012]$, Beta $=.004, p=.819)$, Model $4(95 \% \mathrm{CI}=[-.010, .012]$, Beta $=.004, p=.825)$.

343 There was also no significant interaction between BMI and sex in predicting executive

344 functions in Model $1(95 \% \mathrm{CI}=[-.018, .002]$; Beta=-.026, $p=.123)$, Model $2(95 \% \mathrm{CI}=[-.017$, $345.002]$, Beta $=-.025, p=.128)$, Model $3(95 \% \mathrm{CI}=[-.017, .002]$, Beta $=-.024, p=.137)$, and Model 346 $4(95 \% \mathrm{CI}=[-.018, .001]$, Beta $=-.027, p=.094)$. the four models; Model $1(95 \% \mathrm{CI}=[-.372, .984]$; Beta=.021, $p=.376)$, Model 2 (95\% CI=[$.406, .958]$, Beta $=.019, p=.427)$, Model $3(95 \% \mathrm{CI}=[-.488, .876]$, Beta $=.013, p=.577)$, Model $4(95 \% \mathrm{CI}=[-.487, .877]$, Beta $=.013, p=.575)$. The interaction term between WHR and sex also did not significantly predict executive functions in any of the models; Model $1(95 \%$ $\mathrm{CI}=[-.027,1.201] ; \operatorname{Beta}=.040, p=.061), \operatorname{Model} 2(95 \% \mathrm{CI}=[-.106,1.092]$, Beta $=.034, p=.107)$, Model $3(95 \%$ CI=[-.189, 1.008], Beta=.028, $p=.180)$, Model $4(95 \%$ CI=[-.177, 1.015], Beta $=.029, p=.169)$. The results suggest that the stronger predictability of WHR relative to BMI on episodic memory and executive functions is consistent for both men and women.

\section{Polynomial regressions} BMI and WHR in predicting episodic memory and executive functions in the four different models. For BMI, the quadratic relations between BMI and episodic memory were not significant across all of the four models after controlling for demographic variables in Model $1(95 \% \mathrm{CI}=[-.001, .000], p=.441)$, health status and health behaviours in Model $2(95 \% \mathrm{CI}=[-$ $.001, .000], p=.646)$, personality variables in Model 3 (95\% $\mathrm{CI}=[-.001, .000], p=.604)$, and self-perceived obesity in Model 4 (95\% CI=[-.001, .000], $p=.611)$. There were also no significant quadratic relations between BMI and executive functions in any of the models; 
365 Model $1(95 \% \mathrm{CI}=[-.001, .000], p=.488)$, Model $2(95 \% \mathrm{CI}=[-.001, .000], p=.976)$, Model 3

366

367

368

369

370

371

372

373

374

375

376

377

378

379

380

381

382

383

$(95 \% \mathrm{CI}=[-.001, .000], p=.891)$, Model $4(95 \% \mathrm{CI}=[.000, .001], p=.424)$

Similarly, we did not observe any significant quadratic relations between WHR and episodic memory in any of the models; Model 1 (95\% $\mathrm{CI}=[-.267,2.665], p=.109)$, Model 2 (95\% CI $=[-.461,2.466], p=.179)$, Model $3(95 \% \mathrm{CI}=[-.566,2.358], p=.229)$, and Model 4 $(95 \% \mathrm{CI}=[-.555,2.375], p=.223)$. We also did not observe any significant quadratic relations between WHR and executive functions in Model 1 (95\% CI=[-.673, 1.943], $p=.341)$; Model 2 $(95 \% \mathrm{CI}=[-1.004,1.573], p=.665)$, Model $395 \% \mathrm{CI}=[-1.091,1.485], p=.764)$, and Model 4 $(95 \% \mathrm{CI}=[-.957,1.627], p=.611)$. These findings suggest that the relations between obesity and cognitive functions are unlikely to be quadratic.

\section{Discussion}

Research on adiposity and cognition has routinely found associations between obesity and executive functions, but empirical support for a relationship between obesity and episodic memory has been less forthcoming. While Cheke et al. (2016) presented a decent effort to investigate the obesity-memory link, their study received criticism for having various issues including small sample size, not controlling for health conditions that comorbid with obesity, and the diminished association between BMI and episodic memory when demographic variables were included in the model (Cole \& Pauly-Takacs, 2016). In consideration of these issues and also noting the problems associated with using BMI as a measure of adiposity (cf., Rothman, 2008), we sought to re-examine the relationship between obesity and episodic memory using data from the Cognitive Project of the MIDUS II. The MIDUS II is a large-scale study which comprised numerous participants, assessed participants' BMI, WHR, executive functions, and episodic memory, and included numerous 
measures of potential confounding variables, thus allowing us to simultaneously address the

389

390 aforementioned shortcomings of prior research.

Our analyses showed that WHR is a superior alternative to BMI as a measure of the adverse impact of obesity on episodic memory as well as executive functions. Although BMI rivalled WHR in predicting executive functions and episodic memory while controlling for demographic variables, the effect of BMI on executive functions and episodic memory diminished after health status, health behaviours, personality variables, and self-perceived obesity were added to the model. In contrast, these additional variables did not confound the effect of WHR on episodic memory and executive functions. The current study therefore contributes significantly to the debate on obesity and cognition by demonstrating that WHR surpasses BMI in predicting episodic memory and executive functions across adulthood, at least based on the MIDUS II dataset.

Importantly, the current study also demonstrated a clear link between deficits in episodic memory and higher levels of adiposity as indexed by WHR. By carefully controlling for a wide range of possible confounding factors such as demographic, health-related, personality, and self-perception variables, we found that WHR maintained a distinct effect on episodic memory, thus indicating that obesity is linked to people's ability to store and recall mental representations of experienced or observed events independent of lifestyle or other factors. Our results suggest that not only can impaired episodic memory cause people to overconsume because they fail to recollect prior episodes of eating, but being overweight can also possibly impair episodic memory, which in turn further exacerbates overconsumption. These findings lend support to "vicious cycle" models of obesity and cognitive decline (Kanoski \& Davidson, 2011; Sellbom \& Gunstad, 2012), where high levels of adiposity contribute to cognitive processes that induce ever higher levels of adiposity. In light of our findings, health practitioners should take into account the possibly greater difficulty 
413 experienced by overweight individuals relative to non-overweight individuals in regulating

414

415

consumption behaviours and tailor treatment programs according to the specific needs of overweight individuals.

Our results increase the confidence that continued probing into this area will eventually unearth the specific biological mechanisms that underlie the associations between obesity and episodic memory as well as other aspects of executive function. One candidate mechanism of impaired cognitive function resulting from the accumulation of visceral fat is the secretion of pro-inflammatory cytokines which can result in insulin resistance and worsen cerebrovascular reactivity (Adabimohazab et al., 2016; Lambert, Straznicky, Dixon, \& Lambert, 2015; Miller \& Spencer, 2014). Another possible mechanism for the impairment of cognitive functioning is central and adipose inflammation which plays a significant role in reduced synaptic plasticity (Erion et al., 2014; Willette \& Kapogiannis, 2015). Various researchers are also especially interested in the psychological and behavioural processes that drive impaired cognition and overconsumption, such as whether successful recollection of prior episodes of behaviour is hindered by deficits in encoding or retrieval processes (e.g., Cheke et al., 2016; Sohrabi et al., 2015). Future studies that assess the specific elements of episodic memory deficits are thus needed so that therapists and health practitioners may streamline their treatments more specifically to target patient behavioural deficiencies.

It is important to note some limitations of the current study. Although we were able to rule out a large number of confounding factors and achieve higher confidence in the direct impact of obesity (indexed by BMI and WHR) on episodic memory and executive functions, the findings are correlational and cross-sectional and therefore limit our ability to make causal claims. Further research, in particular longitudinal studies, are warranted to assess the nuanced effects of obesity on cognition and vice versa as these effects unfold over time. 
There may be some concern over the validity of the self-reported BMI in our study.

438 However, we believe that this is unlikely to compromise the overall results because selfreported height and weight have been documented to be adequately reliable and valid in

440 empirical studies on adult samples, even after demographic variables have been controlled

441 (Spencer, Appleby, Davey, \& Key, 2002; Stommel \& Schoenborn, 2009). Furthermore, a subset of participants from the MIDUS II study also participated in a biomarker project where professional clinicians collected their height and weight information (Love, Seeman,

Weinstein, \& Ryff, 2010). The self-reported BMI of the MIDUS II Cognitive Project correlated very strongly with the professionally measured BMI of the MIDUS II Biomarker Project $(r=.922, p<.001)$, thus indicating that the self-reported BMI in the current dataset is probably valid.

Due to the lack of available information on adiposity fat percentage and dietary habits in the MIDUS II dataset, we were unable to assess the effects of adiposity fat percentage (Kamijo et al., 2012) nor were we able to include diet as potential covariates (Kanoski \& Davidson, 2011; Yeomans, 2017), both of which have been shown to be important factors associated with cognitive functioning. Nonetheless, future studies that measure the percentage of adiposity fat when examining the relationship between obesity and cognitive functions while accounting for dietary habits will likely prove promising.

\section{Conclusions}

Taken together, the findings of our study reveal that obesity is not only associated with deficits in executive functions but also episodic memory. However, the adverse links between obesity and cognitive functions only emerged when obesity was measured by WHR and not BMI, highlighting the need for future studies to use more sensitive measures of obesity when examining its relationship with individual differences in cognitive functions. 
Adabimohazab R, Garfinkel A, Milam E. C, Frosch O, Mangone A, \& Convit A. 2016. Does inflammation mediate the association between obesity and insulin resistance? Inflammation. doi:10.1007/s10753-016-0329-z

Adler N. E, Epel E. S, Castellazzo G, \& Ickovics J. R. 2000. Relationship of subjective and objective social status with psychological and physiological functioning: Preliminary data in healthy, White women. Health Psychology, 19(6): 586-592. doi:10.1037/02786133.19 .6 .586

Anstey K. J, Cherbuin N, Budge M, \& Young J. 2011. Body mass index in midlife and latelife as a risk factor for dementia: A meta-analysis of prospective studies. Obesity Reviews, 12(5), 426-437. doi:10.1111/j.1467-789x.2010.00825.x

Avenell A, Broom J, Brown T, Poobalan A, Aucott L, Stearns S, Smith WC, Jung RT, Campbell MK, \& Grant AM. 2004. Systematic review of the long-term effects and economic consequences of treatments for obesity and implications for health improvement. Health Technology Assessment, 8(21): 1-182. doi:10.3310/hta8210

Bendayan R, Piccinin A. M, Hofer S. M, \& Muniz G. 2017. Are changes in self-rated health associated with memory decline in older adults? Journal of Aging and Health, 29(8): 1410-1423. doi:10.1177/0898264316661830

Beydoun MA, Beydoun HA, \& Wang Y. 2008. Obesity and central obesity as risk factors for incident dementia and its subtypes: A systematic review and meta-analysis. Obesity Reviews, 9(3): 204-218. doi:10.1111/j.1467-789x.2008.00473.x

Brunstrom JM, Burn JF, Sell NR, Collingwood JM, Rogers PJ, Wilkinson LL, Hinton EC, Maynard OM, \& Ferriday D. 2012. Episodic memory and appetite regulation in humans. PLoS One, 7(12): e50707. doi:10.1371/journal.pone.0050707 
485 Cheke LG, Simons JS, \& Clayton NS. 2016. Higher body mass index is associated with

486

487

488

489

490

491

492

493

494

495

496

497

498

499

500

501

502

503

504

505

506

507

508

episodic memory deficits in young adults. Quarterly Journal of Experimental Psychology, 69(11): 2305-2316. doi:10.1080/17470218.2015.1099163

Clark DO, Lane KA, Ambuehl R, Tu W, Liu C. J, Unroe K, \& Callahan C. M. 2016. Age Differences in the Association Between Body Mass Index Class and Annualized Medicare Expenditures. Journal of Aging and Health, 28(1): 165-179.

Cole SN, \& Pauly-Takacs K. 2016. Is obesity linked with episodic memory impairment? A commentary on Cheke, Simons, and Clayton (2016). Quarterly Journal of Experimental Psychology, 70(3): 590-591. doi:10.1080/17470218.2016.1173075

Conforto RM, \& Gershman L. (1985). Cognitive processing differences between obese and nonobese subjects. Addictive Behaviors, 10(1): 83-85. doi:10.1016/03064603(85)90056-5

Crowe M, Sartori A, Clay OJ, Wadley VG, Andel R, Wang HX, Sawyer P, \& Allman RM. 2010. Diabetes and cognitive decline: investigating the potential influence of factors related to health disparities. Journal of Aging and Health: 22(3): 292-306. doi:10.1177/0898264309357445

Cserjési R, Luminet O, Poncelet A. S, \& Lénárd L. 2009. Altered executive function in obesity. Exploration of the role of affective states on cognitive abilities. Appetite, 52: 535-539. doi:10.1016/j.appet.2009.01.003

Dohle S, Diel K, \& Hofmann W. 2017. Executive functions and the self-regulation of eating behavior: A review. Appetite. doi:10.1016/j.appet.2017.05.041

Dunai J, Labuschagne I, Castle D. J, Kyrios M, \& Rossell S. L. 2010. Executive function in body dysmorphic disorder. Psychological Medicine, 40(9): 1541-1548. doi:10.1017/s003329170999198x

Peer] reviewing PDF | (2018:04:27679:2:0:CHECK 16 Aug 2018) 
509 Elias MF, Elias PK, Sullivan LM, Wolf PA, \& D'Agostino RB. 2003. Lower cognitive

510

511

512 function in the presence of obesity and hypertension: The Framingham heart study. International Journal of Obesity, 27(2): 260-268. doi:10.1038/sj.ijo.802225

Erion JR, Wosiski-Kuhn M, Dey A, Hao S, Davi, CL, Pollock NK, \& Stranahan AM. 2014. Obesity elicits interleukin 1-mediated deficits in hippocampal synaptic plasticity. Journal of Neuroscience, 34(7): 2618-2631. doi:10.1523/jneurosci.4200-13.2014

Figley C. R, Asem JS. A, Levenbaum EL, \& Courtney, S. M. 2016. Effects of body mass index and body fat percent on default mode, executive control, and salience network structure and function. Neuroscience, 10: 234. doi:10.3389/fnins.2016.00234

Friedman NP, \& Miyake, A. 2017. Unity and diversity of executive functions: Individual differences as a window on cognitive structure. Cortex, 86: 186-204. doi:10.1016/j.cortex.2016.04.023

Gallagher D, Visser M, Sepulveda D, Pierson RN, Harris T, \& Heymsfield SB. 1996. How useful is body mass index for comparison of body fatness across age, sex, and ethnic groups? American Journal of Epidemiology, 143: 228-239. doi:10.1093/oxfordjournals.aje.a009037

Gianaros PJ, Horenstein JA, Cohen S, Matthews KA, Brown SM, Flory JD, Chritchley HD, Manuck SB, \& Hariri AR. 2007. Perigenual anterior cingulate morphology covaries with perceived social standing. Social Cognitive and Affective Neuroscience, 2(3): 161-173. doi:10.1093/scan/nsm013

Goldschmidt AB, O'Brien S, Lavender, JM, Pearson CM, Le Grange D, \& Hunter S. J. 2017. Executive functioning in a racially diverse sample of children who are overweight and at risk for eating disorders. Appetite. doi:10.1016/j.appet.2017.03.010 
532 Gunstad, J, Paul RH, Cohen RA, Tate DF, \& Gordon E. 2006. Obesity is associated with

533 memory deficits in young and middle-aged adults. Eating and Weight Disorders Studies on Anorexia, Bulimia and Obesity, 11(1): e15-e19. doi:10.1007/bf03327747

Gunstad J, Spitznagel MB, Paul RH, Cohen RA, Kohn M, Luyster FS, Clark R, \& Gordon E. 2008. Body mass index and neuropsychological function in healthy children and adolescents. Appetite, 50(2): 246-251. doi:10.1016/j.appet.2007.07.008

Hackman D. A, Farah MJ, \& Meaney MJ. 2010. Socioeconomic status and the brain: mechanistic insights from human and animal research. Nature Reviews Neuroscience, 11(9): 651-659. doi:10.1038/nrn2897

Hartanto A, Toh W. X, \& Yang H. 2016. Age matters: The effect of onset age of video game play on task-switching abilities. Attention, Perception, \& Psychophysics, 78(4): 11251136. doi:10.3758/s13414-016-1068-9

Hartanto A, \& Yang H. 2018. Bilingualism narrows socioeconomic disparities in executive functions and self-regulatory behaviours during early childhood: Evidence from the Early Childhood Longitudinal Study. Child Development. doi: 10.1111/cdev.13032

Hebben N, Corkin S, Eichenbaum H, \& Shedlack K. 1985. Diminished ability to interpret and report internal states after bilateral medial temporal resection: Case H. M. Behavioral Neuroscience, 99(6), 1031-1039.

Higgs S, \& Donohoe J. E. 2011. Focusing on food during lunch enhances lunch memory and decreases later snack intake. Appetite, 57(1), 202-206.

Ihle A, Gouveia ÉR, Gouveia BR, Freitas DL, Jurema J, Machado FT, \& Kliegel M. 2017. The relation of hypertension to performance in immediate and delayed cued recall and working memory in old age: The role of cognitive reserve. Journal of Aging and Health. doi:10.1177/0898264317708883 
556 Janssen I, Katzmarzyk PT, \& Ros, R. 2004. Waist circumference and not body mass index

557

558

559

560

561

562

563

564

565

566

567

568

569

570

571

572

573

574

575

576

577

578

579

580 explains obesity-related health risk. The American Journal of Clinical Nutrition, 79(3): 379-384.

Jurdak N, Lichtenstein, AH, \& Kanarek R. B. 2008. Diet-induced obesity and spatial cognition in young male rats. Nutritional Neuroscience, 11(2): 48-54.

Kamijo K, Khan NA, Pontifex MB, Scudder MR, Drollette ES, Raine LB, Evans EM, Castellie DM, \& Hillman CH. 2012. The relation of adiposity to cognitive control and scholastic achievement in preadolescent children. Obesity, 20(12): 2406-2411. doi:10.1038/oby.2012.112

Kanoski SE, \& Davidson TL. 2011. Western diet consumption and cognitive impairment: Links to hippocampal dysfunction and obesity. Physiology and Behavior, 103(1), 5968. doi:10.1016/j.physbeh.2010.12.003

Kesse-Guyot E, Andreeva VA, Touvier M, Jeandel C, Ferry M, Hercberg S, Galan P, \& The SU.VI.MAX 2 Research Group 2015. Overall and abdominal adiposity in midlife and subsequent cognitive function. Journal of Nutrition, Health, and Aging, 19(2): 183189. doi:10.1007/s12603-014-0508-2

Knopman D, Boland LL, Mosley T, Howard G, Liao D, Szklo M, McGovern P, Folsom AR, \& Atherosclerosis Risk in Communities (ARIC) Study Investigators. 2001. Cardiovascular risk factors and cognitive decline in middle-aged adults. Neurology, 56(1): 42-48. doi:10.1212/wnl.56.1.42

Kopelman PG. 2000. Obesity as a medical problem. Nature, 404(6778): 635-643. doi: $10.1038 / 35007508$

Lachman ME, \& Tun PA. 2008. Cognitive testing in large-scale surveys: Assessment by telephone. In S.M. Hofer \& D.F. Alwin (Eds.), Handbook of cognitive aging: Interdisciplinary perspectives (pp. 506-522). Thousand Oaks, CA: Sage.

Peer] reviewing PDF | (2018:04:27679:2:0:CHECK 16 Aug 2018) 
581 Lambert EA, Straznicky NE, Dixon JB, \& Lambert, G. W. 2015. Should the sympathetic

582

nervous system be a target to improve cardiometabolic risk in obesity? American Journal of Physiology-Heart and Circulatory Physiology, 309(2): H244-H258. doi:10.1152/ajpheart.00096.2015

Lee PL. 2014. Cognitive function in midlife and beyond. The International Journal of Aging and Human Development, 79: 263-278. doi:10.1177/0091415015574190

Martin AA, Davidson TL, \& McCrory MA. 2017. Deficits in episodic memory are related to uncontrolled eating in a sample of healthy adults. Appetite. doi:10.1016/j.appet.2017.05.011

Miller AA, \& Spencer SJ. 2014. Obesity and neuroinflammation: A pathway to cognitive impairment. Brain, Behavior, and Immunity, 42: 10-21. doi:10.1016/j.bbi.2014.04.001

Ng M, Fleming T, Robinson M, Thomson B, Graetz N, Margono C, Mullany EC, Biryukov S, Abbafati C, Abera SF, \& Abraham JP. 2014. Global, regional, and national prevalence of overweight and obesity in children and adults during 1980-2013: A systematic analysis for the Global Burden of Disease Study 2013. The Lancet, 384(9945): 766-781. doi:10.1097/01.aoa.0000472714.57328.86

Nilsson L.-G, \& Nilsson, E. 2009. Overweight and cognition. Scandinavian Journal of Psychology, 50(6): 660-667. doi:10.1111/j.1467-9450.2009.00777.x

O'brien RM. 2007. A caution regarding rules of thumb for variance inflation factors. Quality \& Quantity, 41(5): 673-690. doi:10.1007/s11135-006-9018-6

Preston SH, Fishman E, \& Stokes A. 2015. Effects of categorization and self-report bias on estimates of the association between obesity and mortality. Annals of Epidemiology, 25(12): 907-911.e2. doi:10.1016/j.annepidem.2015.07.012 
605 Price G. M, Uauy R, Breeze E, Bulpitt CJ, \& Fletcher AE. 2006. Weight, shape, and

606

607

608

609

610

611

612

613

614

615

616

617

618

619

620

621

622

623

624

625

626

627

628

629 mortality risk in older persons: Elevated waist-hip ratio, not high body mass index, is associated with a greater risk of death. The American Journal of Clinical Nutrition, 84(2): 449-460.

Raji CA, Ho AJ, Parikshak NN, Becker JT, Lopez OL, Kuller LH, Hua X, Leow AD, Toga AW, \& Thompson PM. 2010. Brain structure and obesity. Human Brain Mapping, 31(3): 353-364.

Reinert KR. S, Po'e EK, \& Barkin SL. 2013. The relationship between executive function and obesity in children and adolescents: A systematic literature review. Journal of Obesity, 820956. doi:10.1155/2013/820956

Rossi, AS. 2001. Caring and doing for others: Social responsibility in the domains of family, work, and community. Chicago, IL: University of Chicago Press.

Rothman, KJ. 2008. BMI-related errors in the measurement of obesity. International Journal of Obesity, 32, S56-S59. doi:10.1038/ijo.2008.87

Rubin DB. 1987. Multiple imputation for nonresponse in surveys. New York, NY: Wiley.

Ryff CD, Almeida DM, Ayanian JS, Carr DS, Cleary PD, Coe C, \& Williams D. 2007. Midlife development in the United States (MIDUS II), 2004-2006. Ann Arbor, MI: Inter-University Consortium for Political and Social Research.

Ryff CD, \& Lachman ME. 2010. National survey of midlife development in the united states (MIDUS II): Cognitive project, 2004-2006 [Data file]. ICPSR25281-v1. Ann Arbor, MI: Inter-university Consortium for Political and Social Research [distributor], 0713.

Sabia S, Kivimaki M, Shipley MJ, Marmot MG, \& Singh-Manoux, A. 2009. Body mass index over the adult life course and cognition in late midlife: The Whitehall II Cohort Study. The American Journal of Clinical Nutrition, 892): 601-607.

Peer] reviewing PDF | (2018:04:27679:2:0:CHECK 16 Aug 2018) 
630 Sellaro R, \& Colzato LS. 2017. High body mass index is associated with impaired cognitive

631 control. Appetite, 113: 301-309. doi:10.1016/j.appet.2017.03.008

632

633

634

635

636

637

638

639

640

641

642

643

644

645

646

647

648

649

650

651

652

653

Sellbom KS, \& Gunstad J. 2012. Cognitive function and decline in obesity. Journal of Alzheimers Disease, 30: S89-95.

Singh-Manoux A, \& Marmot M. 2005. High blood pressure was associated with cognitive function in middle-age in the Whitehall II study. Journal of Clinical Epidemiology, 58(12): 1308-1315. doi:10.1016/j.jclinepi.2005.03.016

Smith E, Hay P, Campbell L, \& Trollor JN. 2011. A review of the association between obesity and cognitive function across the lifespan: Implications for novel approaches to prevention and treatment. Obesity Reviews, 12(9): 740-755. doi:10.1111/j.1467789x.2011.00920.x

Sohrabi HR, Bates KA, Weinborn M, Bucks RS, Rainey-Smith SR, Rodrigues MA, Bird SM, Brown BM, Beilby J, Howard M, \& Criddle, A. 2015. Bone mineral density, adiposity, and cognitive functions. Frontiers in Aging Neuroscience: 7. doi:10.3389/fnagi.2015.00016

Spencer EA, Appleby PN, Davey GK, \& Key TJ. 2002. Validity of self-reported height and weight in 4808 EPIC-Oxford participants. Public Health Nutrition, 5(4): 561-565. doi:10.1079/phn2001322

Stevens J, McClain J. E, \& Truesdale KP. 2008. Selection of measures in epidemiologic studies of the consequences of obesity. International Journal of Obesity, 32: S60-S66. doi:10.1038/ijo.2008.88

Stommel M, \& Schoenborn CA. 2009. Accuracy and usefulness of BMI measures based on self-reported weight and height: Findings from the NHANES \& NHIS 2001-2006. BMC Public Health, 9(1). doi:10.1186/1471-2458-9-421 
654 Tulving E. 2002. Episodic memory: From mind to brain. Annual Review of Psychology,

655

656

657

658

659

660

661

662

663

664

665

666

667

668

669

670

671

672

673

674

675

676

677 53(1): 1-25. doi:10.1146/annurev.psych.53.100901.135114

Tun PA, \& Lachman ME. 2006. Telephone assessment of cognitive function in adulthood: The Brief Test of Adult Cognition by Telephone. Age and Ageing, 35(6): 629-632. doi:10.1093/ageing/af1095

Valladolid-Acebes I, Stucchi P, Cano V, Fernandez-Alfonso MS, Merino B, Gil-Ortega, M, Fole A, Morales L, Ruiz-Gayo M, \& Del Olmo N. 2011. High-fat diets impair spatial learning in the radial-arm maze in mice. Neurobiology of Learning and Memory, 95(1): 80-85. doi:10.1016/j.nlm.2010.11.007

Von Hippel PT. 2007. Regression with missing Ys: An improved strategy for analyzing multiply imputed data. Sociological Methodology, 37(1): 83-117. doi:10.1111/j.14679531.2007.00180.x

Whitmer RA, Gustafson EP, Barrett-Connor E, Haan MN, Gunderson E. P, \& Yaffe, K. 2008. Central obesity and increased risk of dementia more than three decades later. Neurology, 71(14): 1057-1064. doi:10.1212/01.wnl.0000343499.72241.ea

Willette AA, \& Kapogiannis D. 2015. Does the brain shrink as the waist expands? Ageing Research Reviews, 20: 86-97. doi:10.1016/j.arr.2014.03.007

Williams PG, Suchy Y, \& Kraybill ML. 2010. Five-factor model personality traits and executive functioning among older adults. Journal of Research in Personality, 44(4): 485-491. doi:10.1016/j.jrp.2010.06.002

Volkow ND, Wang GJ Telang, F, Fowler JS, Goldstein RZ, Alia-Klein, N, Logan J, Wong C, Thanos PK, Ma Y, \& Pradhan K. 2009. Inverse association between BMI and prefrontal metabolic activity in healthy adults. Obesity, 17(1): 60-65. doi:10.1038/oby.2008.469 
678 Wu M, Brockmeyer T, Hartmann M, Skunde M, Herzog W, \& Friederich HC. 2016. Reward-

679

680

681

682

683

684

685

686

687

688

689

690

691

692

693

694

695

696

697

698

699

700

701 related decision making in eating and weight disorders: A systematic review and meta-analysis of the evidence from neuropsychological studies. Neuroscience and Biobehavioral Reviews, 61: 177-196. doi:10.1016/j.neubiorev.2015.11.017

Yeomans MR. 2017. Adverse effects of consuming high fat-sugar diets on cognition: implications for understanding obesity. Proceedings of the Nutrition Society, 76(04): 455-465. doi:10.1017/s0029665117000805

York R. 2012. Residualization is not the answer: Rethinking how to address multicollinearity. Social Science Research, 41(6): 1379-1386. doi:10.1016/j.ssresearch.2012.05.014

Zhang F, Fung H, \& Kwok T. 2017. Spouse's subjective social status predicts older adults' prospective cognitive functioning. Aging \& Mental Health: 1-9. doi:10.1080/13607863.2017.1406449

Zhu S, Heymsfield SB, Toyoshima H, Wang Z, Pietrobelli A, \& Heshka S. 2005 Raceethnicity-specific waist circumference cutoffs for identifying cardiovascular disease risk factors. American Journal of Clinical Nutrition, 81: 409-415.

Zore T, Palafox M, \& Reue K. 2018. Sex differences in obesity, lipid metabolism, and inflammation-A role for the sex chromosomes? Molecular Metabolism, 15: 35-44. doi:10.1016/j.molmet.2018.04.003 


\section{Table $\mathbf{1}$ (on next page)}

Descriptive statistics for obesity, cognitive functions, demographics, health status, health behaviours, and personality characteristics 
1 Table 1.

2 Descriptive Statistics for Obesity, Cognitive Functions, Demographics, Health Status, Health

3 Behaviours, and Personality Characteristics

\begin{tabular}{|c|c|c|c|}
\hline & $M$ & $S D$ & Range \\
\hline \multicolumn{4}{|l|}{ Demographic } \\
\hline Mean age (years) & 56.49 & 12.35 & $32-84$ \\
\hline Sex ( $\%$ of male $)$ & $45 \%$ & & \\
\hline Education $^{1}$ & 7.28 & 2.54 & $1-12$ \\
\hline Household income (\$) & 57,081 & 55,217 & $0-200,000$ \\
\hline Subjective social status & 4.49 & 1.82 & $1-10$ \\
\hline \multicolumn{4}{|l|}{ Health Status } \\
\hline Number of chronic disease ${ }^{2}$ & 2.44 & 2.38 & $0-13$ \\
\hline Stroke & $1 \%$ & & \\
\hline Hypertension & $31 \%$ & & \\
\hline Diabetes & $10 \%$ & & \\
\hline Physical health evaluation & 2.44 & 1.01 & $1-5$ \\
\hline \multicolumn{4}{|l|}{ Health behaviours } \\
\hline Non-smoker $(\%)$ & $52 \%$ & & \\
\hline Former smoker $(\%)$ & $34 \%$ & & \\
\hline Current smoker (\%) & $14 \%$ & & \\
\hline Alcohol consumer $(\%)$ & $59 \%$ & & \\
\hline \multicolumn{4}{|l|}{ Personality $^{3}$} \\
\hline Neuroticism & 2.06 & 0.62 & $1-4$ \\
\hline
\end{tabular}


Openness to experience

Conscientious

Extraversion

Agreeableness

Obesity

Body mass index ${ }^{2}$

Waist-to-hip ratio ${ }^{2}$

Cognitive functions
2.90

3.46

3.10

3.45

27.89

0.91

0.01

0.00
0.54

0.45

0.57

0.50

5.67

0.11

$0.50-1.32$

Episodic memory (z-score)

1.01

$-3.07-3.83$

Executive functions ( $z$-score)

0.99

$-4.80-3.39$

$4 \quad$ Note. SDs are shown in parentheses.

$5{ }^{1}$ Education attainment was rated on a scale of 1 (No school) to 12 (Ph.D, ED. D, MD, LLB, LLD,

6 JD, or other professional degree)

$7 \quad{ }^{2}$ Values were winsorized to reduce the effect of extreme outliers

$8{ }^{3}$ Each personality score was computed by averaging the respective personality items (Rossi,

9 2001) rated on a four-point Likert scale $(1=$ not at all, $4=$ a lot $)$, with higher scores indicating a

10 higher amount of that particular personality dimension (e.g., greater neuroticism). 
Table 2 (on next page)

Overview and descriptive statistics of cognitive function measures 
Table 2.

2 Overview and Descriptive Statistics of Cognitive Function Measures

\begin{tabular}{|c|c|c|c|c|c|}
\hline Measures & Theoretical Construct & Performance Index & Procedure & $M(S D)$ & Range \\
\hline $\begin{array}{l}\text { Immediate word } \\
\text { list recall task }\end{array}$ & $\begin{array}{l}\text { Episodic verbal } \\
\text { memory }\end{array}$ & $\begin{array}{c}\text { Total number of accurate } \\
\text { responses }\end{array}$ & $\begin{array}{l}\text { Participants were presented with } 15 \text { words and } \\
\text { instructed to recall the items }\end{array}$ & $6.74(2.30)$ & $0-15$ \\
\hline $\begin{array}{l}\text { Backward digit } \\
\text { span }\end{array}$ & Working memory & $\begin{array}{l}\text { Highest number of digits } \\
\text { recalled up to } 8\end{array}$ & $\begin{array}{l}\text { Participants were given a series of numbers and } \\
\text { instructed to recall the numbers backwards }\end{array}$ & $5.01(1.50)$ & $0-8$ \\
\hline Categorical fluency & $\begin{array}{l}\text { Verbal ability and } \\
\text { speed of processing }\end{array}$ & $\begin{array}{l}\text { The frequency of unique } \\
\text { responses generated }\end{array}$ & $\begin{array}{l}\text { Participants were instructed to produce as many } \\
\text { words as possible from each given category within } \\
\text { a minute }\end{array}$ & $18.80(6.17)$ & $0-42$ \\
\hline $\begin{array}{l}\text { Delayed word list } \\
\text { recall task }\end{array}$ & $\begin{array}{l}\text { Episodic verbal } \\
\text { memory and forgetting }\end{array}$ & $\begin{array}{c}\text { Total number of accurate } \\
\text { responses }\end{array}$ & $\begin{array}{l}\text { Participants were presented with } 15 \text { words and } \\
\text { instructed to recall the items after a long delay }\end{array}$ & $4.45(2.63)$ & $0-14$ \\
\hline Number series & $\begin{array}{l}\text { Inductive reasoning and } \\
\text { fluid intelligence }\end{array}$ & $\begin{array}{l}\text { Total number of accurate } \\
\text { responses }\end{array}$ & $\begin{array}{l}\text { Participants were given strings of numbers and } \\
\text { instructed to deduce the next number in the series }\end{array}$ & $2.28(1.52)$ & $0-5$ \\
\hline $\begin{array}{l}\text { Backward counting } \\
\text { task }\end{array}$ & Speed of processing & $\begin{array}{l}\text { Total number of accurate } \\
\text { responses, derived from } \\
\text { the last number reached, } \\
\text { taking off from errors }\end{array}$ & $\begin{array}{l}\text { Participants were instructed to count backwards } \\
\text { from } 100\end{array}$ & $37.15(11.31)$ & $-2-90$ \\
\hline $\begin{array}{l}\text { Stop and Go } \\
\text { Switch Task }\end{array}$ & $\begin{array}{l}\text { Inhibitory control and } \\
\text { task-switching }\end{array}$ & $\begin{array}{l}\text { The average of reaction } \\
\text { time differences between } \\
\text { incongruent trials and }\end{array}$ & $\begin{array}{l}\text { Participants were instructed to complete two } \\
\text { single-task blocks and a mixed-task block. In the } \\
\text { first single-task block, all of the trials were }\end{array}$ & $1.09(0.25)$ & $\begin{array}{l}0.22- \\
3.82\end{array}$ \\
\hline
\end{tabular}


congruent trials

(inhibitory control) and reaction time differences

between switch trials and nonswitch trials (taskswitching) congruent trials where participants were instructed

to give a verbal response "stop" and "go" as quickly as possible when they heard the words "red" and "green," respectively. In the second single-task block, all of the trials were incongruent where participants were instructed to respond with "go" and "stop" when they heard "red" and green," respectively. In the mixed block, participants were required to alternate between congruent and incongruent rules based on the cue presented ("normal" or "reverse") by the experimenter 


\section{Table 3 (on next page)}

Model summaries of episodic memory and executive functions with BMI as the predictor 
1 Table 3.

2 Model Summaries of Episodic Memory and Executive Functions with BMI as the Predictor

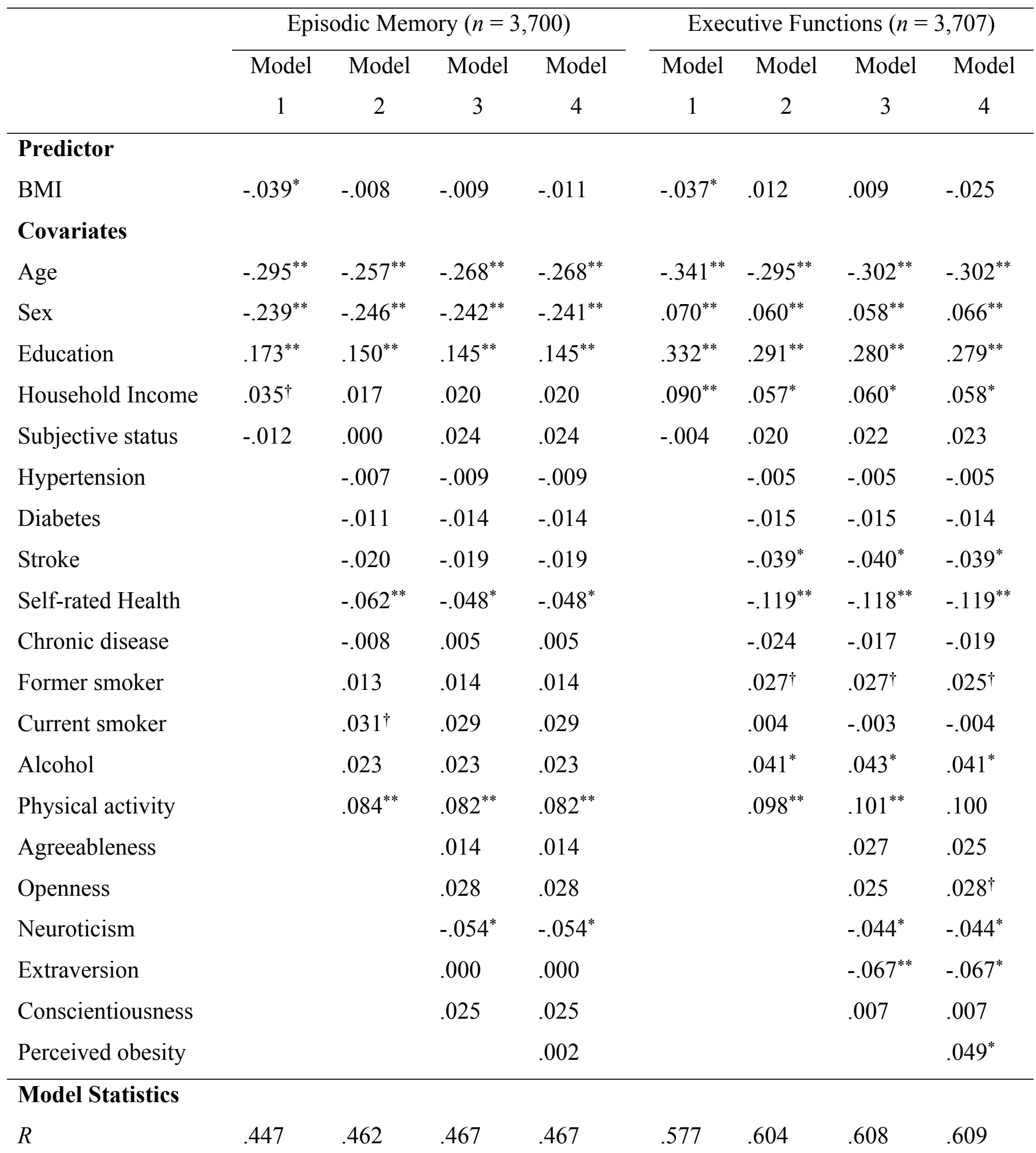




\begin{tabular}{lllllllll}
$R^{2}$ & .200 & .213 & .219 & .219 & .333 & .365 & .370 & .371 \\
$R^{2}$ Change & $.200^{* *}$ & $.014^{* *}$ & $.005^{* *}$ & .000 & $.333^{* *}$ & $.033^{* *}$ & $.004^{* *}$ & $.001^{*}$ \\
\hline
\end{tabular}

3 Note: BMI, age, sex, education, household income, and subjective socioeconomic status (SES)

4 were included in the Model 1. Hypertension, diabetes, stroke, self-reported physical health, the

5 total number of chronic diseases, smoking, alcohol consumption, and physical activity were

6 further included as covariates in the Model 2. Big five personality traits, including extraversion,

7 conscientiousness, agreeableness, neuroticism, and openness to experience, were further

8 included as covariates in the Model 3. Self-perceived obesity was additionally included as a

9 covariate in the Model 4. Sex was coded with female as reference. Former and current smoker

10 were coded with non-smoker as reference. Regular alcohol intake was coded with non-drinker as

11 reference. Hypertension, diabetes, and stroke were coded with no respective health condition

12 experienced for the last 12 months as reference. Model statistics were based on the first imputed

13 dataset. ${ }^{\dagger} p<.10,{ }^{*} p<.05,{ }^{* *} p<.001$. 


\section{Table 4 (on next page)}

Model summaries of episodic memory and executive functions with waist-to-hip ratio as the predictor 
1 Table 4.

2 Model Summaries of Episodic Memory and Executive Functions with Waist-to-hip Ratio as the 3 Predictor

\begin{tabular}{|c|c|c|c|c|c|c|c|c|}
\hline & \multicolumn{4}{|c|}{ Episodic Memory $(n=3,700)$} & \multicolumn{4}{|c|}{ Executive Functions $(n=3,707)$} \\
\hline & Model & Model & Model & Model & Model & Model & Model & Model \\
\hline & 1 & 2 & 3 & 4 & 1 & 2 & 3 & 4 \\
\hline \multicolumn{9}{|l|}{ Predictor } \\
\hline Waist-to-hip Ratio & $-.069^{* *}$ & $-.049^{*}$ & $-.047^{*}$ & $-.047^{*}$ & $-.091^{* *}$ & $-.059^{*}$ & $-.060^{* *}$ & $-.070^{* *}$ \\
\hline \multicolumn{9}{|l|}{ Covariates } \\
\hline Age & $-.293^{* *}$ & $-.257^{* *}$ & $-.268^{* *}$ & $-.267^{* *}$ & $-.338^{* *}$ & $-.300^{* *}$ & $-.306^{* *}$ & $-.301^{* *}$ \\
\hline Sex & $-.202^{* *}$ & $-.219^{* *}$ & $-.215^{* *}$ & $-.215^{* *}$ & $.119^{* *}$ & $.094^{* *}$ & $.094^{* *}$ & $.104^{* *}$ \\
\hline Education & $.172^{* *}$ & $.148^{* *}$ & $.144^{* *}$ & $.144^{* *}$ & $.329^{* *}$ & $.288^{* *}$ & $.277^{* *}$ & $.277^{* *}$ \\
\hline Household Income & $.032^{\dagger}$ & .015 & .018 & .018 & $.085^{* *}$ & $.055^{*}$ & $.058^{* *}$ & $.055^{*}$ \\
\hline Subjective status & -.011 & .001 & .025 & .025 & -.002 & .021 & .022 & .023 \\
\hline Hypertension & & -.006 & -.009 & -.009 & & .000 & -.001 & -.006 \\
\hline Diabetes & & -.010 & -.014 & -.014 & & -.011 & -.012 & -.015 \\
\hline Stroke & & -.020 & -.019 & -.018 & & $-.040^{*}$ & $-.040^{*}$ & $-.038^{*}$ \\
\hline Self-rated Health & & $-.060^{*}$ & $-.046^{*}$ & $-.047^{*}$ & & $-.113^{* *}$ & $-.113^{* *}$ & $-.118^{* *}$ \\
\hline Chronic disease & & -.007 & .006 & .006 & & -.020 & -.015 & -.018 \\
\hline Former smoker & & .013 & .014 & .014 & & $.026^{\dagger}$ & $.027^{\dagger}$ & $.025^{\dagger}$ \\
\hline Current smoker & & $.032^{*}$ & $.030^{\dagger}$ & $.031^{\dagger}$ & & .003 & .003 & .007 \\
\hline Alcohol & & .022 & .022 & .022 & & $.039^{*}$ & $.041^{*}$ & $.041^{*}$ \\
\hline Physical exercise & & $.082^{* *}$ & $.080^{* *}$ & $.080^{* *}$ & & $.094^{* *}$ & $.098^{* *}$ & $.098^{* *}$ \\
\hline Agreeableness & & & .016 & .015 & & & $.030^{\dagger}$ & .027 \\
\hline Openness & & & .027 & .027 & & & .024 & .026 \\
\hline Neuroticism & & & $-.053^{*}$ & $-.053^{*}$ & & & $-.044^{*}$ & $-.043^{*}$ \\
\hline Extraversion & & & -.001 & -.001 & & & $-.069^{* *}$ & $-.068^{* *}$ \\
\hline Conscientiousness & & & .024 & .023 & & & .004 & .005 \\
\hline Perceived obesity & & & & .003 & & & & $.044^{*}$ \\
\hline
\end{tabular}

\section{Model Statistics}




$\begin{array}{lllllllll}R & .449 & .464 & .469 & .469 & .580 & .606 & .610 & .611 \\ R^{2} & .202 & .215 & .220 & .220 & .337 & .367 & .372 & .373 \\ R^{2} \text { Change } & .202^{* *} & .014^{* *} & .005^{* *} & .000^{* *} & .337^{* *} & .031^{* *} & .005^{* *} & .002^{*}\end{array}$

4 Note: Waist-to-hip ratio, age, sex, education, household income, and subjective socioeconomic 5 status (SES) were included in the Model 1. Hypertension, diabetes, stroke, self-reported physical

6 health, the total number of chronic diseases, smoking, alcohol consumption, and physical activity

7 were further included as covariates in the Model 2. Big five personality traits, including

8 extraversion, conscientiousness, agreeableness, neuroticism, and openness to experience, were

9 further included as covariates in the Model 3. Self-perceived obesity was additionally included as

10 a covariate in the Model 4. Sex was coded with female as reference. Former and current smoker

11 were coded with non-smoker as reference. Regular alcohol intake was coded with non-drinker as

12 reference. Hypertension, diabetes, and stroke were coded with no respective health condition

13 experienced for the last 12 months as reference. Model statistics were based on the first imputed

14 dataset. ${ }^{\dagger} p<.10,{ }^{*} p<.05,{ }^{* *} p<.001$. 